\title{
Entre Bandeiras e Mantos: Aparecida e a identidade nacional brasileira
}

Resumo

Nas vestes das esculturas sacras se veem bandeiras nacionais, a exemplo do manto atual de Nossa Senhora Aparecida, a padroeira do Brasil desde o Governo nacionalista de Getúlio Vargas. Essas bandeiras celebram uma conformidade nacional e unem a arte sacra à política e à cultura. Aqui, leremos as vestimentas da estatuária cristã à luz das relações entre a Igreja Católica e o Estado, mediadas pelo tecido como um artefato estético, político e religioso.

Palavras-chave:

Nossa Senhora Aparecida, esculturas sacras vestidas, bandeiras nacionais 


\section{Between Flags and Mantles: Aparecida and the Brazilian national identity}

FUVIANE GALDINO MOREIRA

\section{Abstract}

In the vestments of the sacred sculptures we see national flags, such as the current mantle of Our Lady Aparecida, the patroness of Brazil, since Getulio Vargas' nationalist government. These flags celebrate a national conformity and the sacred art and the national flags, tying religion, politics and culture. Here, we will read the vestments of the Christian statuary in the Catholic Church and the State, mediated by the fabric as an aesthetic, political and religious artifact. 


\section{Entre banderas y mantos: Aparecida y la identidad nacional brasileña}

FUVIANE GALDINO MOREIRA

\section{Resumen}

En los vestuarios de las esculturas sagradas se observan banderas nacionales, a ejemplo del manto actual de Nossa Senhora Aparecida, la patrona del Brasil desde el gobierno nacionalista de Getúlio Vargas. Esas banderas celebran una armonía nacional y mezclan el arte sagrado, la política y la cultura. Aquí analizaremos los trajes de la escultura cristiana a la luz de las relaciones entre la Iglesia Católica y el Estado intermediadas por el tejido como un artefacto estético, político y religioso.

Palabras clave:

Nuestra Señora Aparecida, esculturas sagradas trajeadas, banderas nacionales 


\section{Introdução}

Com base na pesquisa realizada no Trabalho de Conclusão do Curso de Artes Plásticas e na dissertação de mestrado em Artes, ambos vinculados ao tema Vestuário e Arte Sacra, despontou- me o interesse pelo conhecimento e compreensão dos usos e das funções das vestes em imagens cristãs católicas. Uma vez que esse tema é pouco estudado na História da Arte, pensamos ser relevante este estudo como subsídio a pesquisas congêneres.

Conforme Albert-Llorca (2013), a prática de vestir as esculturas com tecido se expande no mundo católico desde o fim da Idade Média, "mas os historiadores, historiadores da arte e antropólogos do cristianismo há muito tempo ignoram sua importância"1 (ALBERT-LLORCA, 2013, p. 1-2, tradução nossa). "Condenada pelos historiadores da arte porque mascara as esculturas que incluem vestidos e mantos, ela igualmente foi rejeitada pelos religiosos que veem nela uma prática idólatra ou, do contrário, profana" (ALBERT-LLORCA, 2013, p. 1-2, tradução nossa).

Vestir as esculturas é um costume que vigorou durante o Medievo, mas que foi questionado no século XVI, quando a Reforma Protestante (1517) acendeu no catolicismo a necessidade de uma adequação de suas diretrizes aos questionamentos existentes na ambiência social e cultural da época. Assim, a Contrarreforma promulgada pela Igreja Católica buscou conter o excesso e os abusos na utilização da imagem (DELFOSSE, 2004). De acordo com Argolo (2014), dentre as muitas acusações que os luteranos e os calvinistas direcionavam contra os católicos no movimento protestante, a libertinagem estava incluída como um dos pontos centrais. Por isso, algumas deter- 
minações do Concílio de Trento influenciaram nas formas de manifestação artística existentes naquele período, determinando-se o cumprimento das normas de decoro e decência nas pinturas sagradas como uma espécie de reação contra a acusação de idolatria, feita pela Reforma Protestante. Cita-se, de acordo com SCHEFFLER (1999, p. 22, tradução nossa) uma queixa do decreto da vigésima quinta sessão dessa conferência:

Na evocação dos santos, na veneração das relíquias e no uso sagrado das imagens [deve-se evitar] toda lascívia, por isso, as imagens não devem ser pintadas ou adornadas com encantos sedutores [...] Finalmente [...] não deve aparecer nada que seja profano. ${ }^{2}$

Compreendemos, então, que no Concílio de Trento (15451563), impôs-se um severo controle para evitar que a igreja fosse vinculada à ideia de idolatria. Basta nos reportarmos ao evento que ocorreu na Capela Sistina, especialmente no que concerne à pintura de Michelangelo sobre o Juízo Final, executada entre 1536 e 1541. Michelangelo pintou personagens bíblicos nus em cenas do Juízo Universal na Capela Sistina, localizada na Itália. Diante disso, a Congregação do Concílio de Trento, em 1564, impôs que se cobrissem algumas das figuras dessa Capela, mais precisamente as do julgamento, aquelas consideradas "obscenas". Com isso, essas imagens passaram a ter drapeados, as chamadas "bragas", feitas pelo artista Daniele Ricciarelli da Volterra que, desde então, passou a ser conhecido como braghetonne (põe bragas) (MOREIRA, 2009).

No concílio suprarreferido, houve uma rejeição das representações que a Igreja católica considerava lascivas ou profanas, ou portadoras de falsos dogmas e superstições, abominando-se as representações de nudez. Em contrapartida, é importante ressaltar que os temas e imagens utilizados pelos artistas do Renascimento e dos primeiros tempos do maneirismo, até mesmo por serem de um tempo anterior, não atendiam a esses preceitos. De todo modo, ratificamos o que nos mostra Delfosse (2004): a igreja exige em sua Contrarreforma uma grande moderação nas representações iconográficas do Cristo e dos Santos. Isso anuncia como os concílios do catolicismo têm grandes influências na feitura das esculturas cristãs, e consequentemente, em seus modos vestimentares.

$\mathrm{O}$ costume de vestir as imagens esculpidas de forma humana também foi considerado por Trexler (1991) como um dos assuntos mais negligenciados da história das artes visuais. 
De todo modo, concordamos com esse autor quando expõe a importância desse tema para a compreensão do comportamento humano e dos objetos artísticos.

É a partir do estudo dessa prática que investigamos as funções exercidas pela veste nas esculturas sacras, de um modo mais específico, focando neste artigo a função identitária que as vestimentas desempenham na imaginária religiosa. Isso se reverbera aqui a partir da presença de bandeiras nos mantos da Virgem Maria, mais precisamente, em nosso caso, da padroeira do Brasil: Nossa Senhora Aparecida. Optamos por essa padroeira, sobretudo, devido ao seu caráter histórico-social. Uma imagem de escultura "mestiça", considerada padroeira brasileira em 1931, ano em que Getúlio Vargas se configurava como presidente deste país, num cenário de discurso nacionalista e de busca pela formação de uma identidade nacional.

\section{Aparecida e a identidade nacional}

Quando citamos o início do governo de Getúlio Vargas, referimo-nos a uma sociedade legalmente laica, diante da promulgação da Constituição de 1891, advinda com a proclamação da República em 1889. Com essa Constituição, sobreveio o fim do sistema de padroado 3 e, consequentemente, uma potencial e aparente perda da hegemonia da Igreja Católica na esfera política do país. O fim ilusório dessa quebra de ligação entre Estado e Igreja na República trouxe consequências para o catolicismo. Por exemplo: instituiu-se o casamento civil, entregaram-se os cemitérios para as prefeituras, decretou-se o fim do ensino religioso nas escolas públicas, assim como se determinou o não pagamento do salário do Clero pelo Estado (SILVA, 2012).

Quando Vargas toma posse como governador provisório em 1931, inicia uma fase de reunificação da relação entre Igreja e Estado no Brasil. Vargas contou com o apoio de Dom Sebastião Leme, que, em 1930, teria aconselhado o Presidente Washington Luís a renunciar à Presidência da República (VASCONCELOS, 2015).

De todo modo, esse período laico, pós-proclamação da República, será absorvido pelo catolicismo como elemento estimulador de novas acomodações entre religião e política, mediadas pela sutileza simbólica das vestes de Aparecida. As fotografias mais antigas dessa escultura nos mostram que a presença das bandeiras do Brasil e do Vaticano no manto de Aparecida só vai ocorrer após o ano de 1931, quando a imagem é considerada padroeira brasileira. 
Historicamente, a presença de bandeiras nas vestimentas da Virgem Maria remonta à Idade Média. Trexler (1991, p. 213, tradução nossa) nos informa de que "[...] havia, no entanto, importantes peças de tecido puro que se utilizavam para cobrir as Virgens"4, e que vistos como mantos estariam relacionados segundo Padre Trens apud Trexler (1991, p. 211) "a um ar sacerdotal, verdadeiramente viril (masculino)".

Assim, esse autor se refere a estandartes e relíquias vestimentares utilizadas como bandeiras. Dentro dessa perspectiva, supomos que a bandeira seja um instrumento que reforça o sentimento de pertencimento a dada região ou país. Num caráter identitário, compartilhamos da ideia de Bartholeyns (2012, p. 116, tradução nossa) quando nos diz que "as vestimentas comunicam em primeiro lugar uma identidade 'social'"'. Exemplifica-o, a toga do antigo cidadão greco-romano, que hoje, de uma forma diferenciada, veste o advogado. Também podemos citar o manto do oficial da antiguidade, que comunicava sua patente por meio de signos, cores e tipos de tecidos, assim outros tipos de vestuário identificam, hoje, pela aparência, a condição cultural de determinado extrato social, exprimindo uma hierarquia socioeconômica ou uma marca de superioridade militar.

No que se refere às imagens sacras, $o$ ato de vestir as esculturas lhes confere uma nova forma de representação. Puccio (2002), em seu artigo "Mais Vale vestir Santos que despir bêbados", se refere a um provérbio aragonês, de oposição ao eterno gesto das mulheres que dormem com seus maridos quando eles retornam bêbados para casa, diante do ato habitual de meninas que, durante as festividades locais, ornam as esculturas da igreja. Alternadamente, todas as meninas em idade de casar, habitantes de San Juan de Plan ${ }^{6}$, devem se submeter a essa obrigação. "A cada ano, durante a festa patronal, cinco senhoritas são nomeadas "assistentes religiosas" por cinco rapazes, escolhidos entre os jovens solteiros da Aldeia dos Pirineus."7 (PUCCIO, 2002, p. 142, tradução nossa).

Em San Juan de Plan, cada família quer contribuir para a fabricação do vestido de Maria. Mesmo sabendo que as "assistentes religiosas" irão selecioná-lo segundo seu gosto pessoal, as peças são procuradas: "é preciso tentar agradar a todos" (PUCCIO, 2002, p. 143, tradução nossa).

Quanto à imagem de Nossa Senhora Aparecida, foi considerada padroeira do Brasil por meio do decreto assinado em 16 de julho de 1930, pelo Papa PIO XI. Contudo, a cerimônia oficial de proclamação de Aparecida só ocorreu em 31 de maio de 
1931. Essa escultura é de terracota, mede $36 \mathrm{~cm}$ de altura e pesa $2 \frac{1}{2} \mathrm{~kg}$, segundo Böing (2007). Tem-se em consideração que a própria estrutura da estatuária é dotada de vestimenta, mas que pela inclusão do manto, trata-se, portanto, de uma peça inteira, de terracota, que teve uma complementação de vestes.

Na relação da Igreja Católica com o Estado a partir da imagem de Aparecida, indicamos a existência da inclusão da Virgem Maria num contexto político-religioso que se firma a partir dos emblemas vigentes no manto dessa escultura, portador de bandeiras religiosa e nacional, respectivamente. Maria, dessa forma, entra no discurso político de nossa sociedade. Mas é importante ressaltar, pensando-se em outros tempos históricos, que essa posição da Virgem não é inerente somente ao contexto sociopolítico do país. Figueras (1999 apud Delfosse, 2012).

admite que grande parte dos historiadores destaca a integração da iconografia mariana na legitimação de poderes na Idade Média. Basta que nos lembremos das bandeiras que, como aborda Trexler (1991), podiam ser usadas nas representações de Nossa Senhora. A Virgem podia ser apresentada como uma espécie de mensageira oficial do Medievo, tal como os servos, igualmente revestidos com os brasões de seus senhores. Delfosse (2004, p. 206, tradução nossa) nos diz que "o Vestuário, enfim, substitui o fenômeno de apropriação da figura de Maria, e, portanto, de intensificação do sentimento de identi-

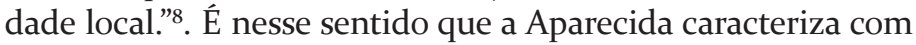
eloquência um tipo de construção identitária. Além disso, da mesma maneira que Albert-Llorca (1994) o faz, admitimos que na celebração de uma santa como padroeira é a própria identidade da nação, cidade ou região que é celebrada.

Ortiz (2006) discorre sobre o conceito de nação, relacionando-o a uma forma de organização da sociedade que associa grupos de características variadas dentro de um mesmo território geográfico, a fim de formar uma unidade moral, mental e intelectual. Na concepção de Anderson (2008, p. 32), o conceito de nação se refere a "[...] uma comunidade política imaginada”. Como nos informa esse último autor, as mudanças ocorridas nas religiões confeririam aos nacionalismos certas soluções seculares para a sua consolidação e continuidade que, antes nas cidades antigas, eram reivindicadas pelas crenças religiosas pagãs, panteístas, maniqueístas ou monoteístas, como as investigou Coulanges (2006).

No que concerne à relação entre bandeira e religiosidade, Coimbra (200o) direciona o nosso olhar para os tempos de 
Constantino. No ano de 313, Constantino publicou o Edito de Milão, que em essência dava liberdade aos cristãos, até então perseguidos e martirizados. Houve, dessa forma, uma ligação entre a igreja e o governo. No Brasil, após a Proclamação da República, em 1889, Igreja e Estado se separaram juridicamente, o que também alterou a disposição de sua bandeira.

Coimbra nos apresenta que nessa ligação entre a bandeira e a doutrina católica, a devoção mariana também se torna presente, quando se enfatiza a independência dos países da América Latina. Como demonstra esse autor (COIMBRA, 2000, p. 78),

[...] Muito notável, porém, é que as bandeiras do Novo Continente não se tenham deixado influenciar pela Tricolor da Revolução Francesa, cujo pensamento, mais que o da norte-americana, impregnou as gerações que prepararam, construíram e consolidaram a liberdade de nossos países. Duas outras inspirações guiaram o layout de nossos pavilhões: a força telúrica e a devoção mariana.

No caso da força telúrica, essa se manifesta de acordo com a presença dos símbolos de cada país: folhas, ramos ou árvores, plumas e animais. Em relação ao culto mariano, "na cor azul, completada algumas vezes pelo branco, símbolo do manto bicrômico da Imaculada Conceição" (COIMBRA, 2000, p. 78), sua devoção foi trazida pelos iberos para as terras de Colombo. De todo modo, a cruz só aparece hoje na bandeira da República Dominicana.

Quanto à devoção mariana na América Latina, essa relação com a bandeira tem conexão direta com as palavras de Souza (2001), ao afirmar que a Virgem Maria é um dos símbolos femininos mais fortes do mundo ocidental católico. Maria, portanto, se consolida como mediadora do povo cristão junto a Deus. "[...] Mais que isso: na América, identificando-se com a cor de negros, índios e mestiços, fazia-se a mediadora cultural entre o universo letrado e o mundo a ser conquistado pela fé católica" (SOUZA, 2001, p. 91). Ainda segundo essa autora (SOUZA, 2013), nos direcionando para o corpus deste trabalho, Aparecida tinha tudo para ser um traço de ligação simbólica entre todas as etnias e degraus sociais que habitavam a nação mestiça, católica, assim como republicana.

Vale lembrar que tanto a celebração romântica do índio quanto a exaltação do mestiço são acomodações que carrearam avanços e recuos em relação à população pobre deste 
país, pois ambas mascaram a relevância do negro, como etnia explorada para conferir lucros aos senhores de engenho, fazendas e minerações, nos períodos colonial e monárquico.

Dessa forma, compreender a imagem de escultura de Nossa Senhora Aparecida, e, mais precisamente, o seu vestuário, vai além da imagem que se vê, pois, podemos perceber nela uma multiplicidade de movimentos históricos, antropológicos que se interpõem no percurso entre o visto e o vivido.

\section{Métodos de análise da pesquisa}

Nossas pesquisas sobre as transformações e trajetórias dos mantos de Aparecida se despontam a partir dos estudos realizados para a tese de doutorado (MOREIRA, 2017). Por enquanto, fazemos um arrolamento de todos os mantos de Aparecida, disponibilizados em livros e nos arquivos documentais da Basílica de Aparecida (SP). Esta pesquisa se medeia, dessa forma, por um levantamento bibliográfico e fotográfico da imagem de escultura original dessa representação de Nossa Senhora, assim como pela identificação das fotografias e dos documentos históricos sobre o seu vestuário.

Num sentido comparativo, analisamos as vestes de Aparecida, identificando em seu tecido a presença de elementos que correspondem aos símbolos nacionais, por exemplo, a bandeira do Brasil. Para o entendimento mais claro dos mantos atual e anteriores dessa imaginária, também vimos como necessário um breve estudo e apresentação sobre as características ornamentais das bandeiras.

Desse modo, tendo em vista o que apresenta Coimbra (2000), o mais antigo de todos os documentos sobre Bandeira é o Estandarte de $\mathrm{Ur}^{9}$, quando o homem já havia passado para a fase de linguagem escrita, havendo uma definida organização social. A cidade de Ur é citada em textos bíblicos, tal como podemos observar em Gênesis capítulo 11, versículo 31 "Taré tomou seu filho Abrão, seu neto Lot, filho de Arão, e Sarai, sua nora, mulher de Abrão, seu filho, e partiu com eles de Ur da Caldéia, indo para a terra de Canãa”.

Ademais, para explicar como a bandeira se expandiu para outros povos, Coimbra (2000, p. 38) nos mostra que "Existiam primitivamente no Egito, várias tribos de origem afro-asiática, que se uniram depois em nomos, e em seguida em dois reinos, o do Norte e o do Sul". Segundo esse autor, o uso de um objeto como símbolo grupal estava presente nas origens dessas tribos. 
[...] Usaram estes povos primitivos, segundo Diodoro de Sicília, feixes de ervas amarrados a hastes. Era uma insígnia simples, fácil de ser confeccionada. A Bandeira nascia, assim, de um consórcio entre o homem e a terra; surgia da árvore, essência criadora e símbolo de proteção (COIMBRA, 2000, p. 38).

Para Maia apud Coimbra (200o), o berço da bandeira seria, portanto, o vegetal, onde se concentram todas as belezas, religiões e segredos. Os soldados romanos amarravam feixes de feno a estacas. Os revolucionários franceses, como pontua o autor (COIMBRA, 200o, p. 39), "[se ornaram] com folhas de árvores como símbolo do grande partido nacional”. Em 1822, os brasileiros também recorreram ao cróton variegatum de folhas verdes com nervuras amarelas, como estandarte popular no início da nova nacionalidade, sentimento consolidado oficialmente na bandeira imperial pela presença de dois produtos: fumo e café. A República brasileira conservou no brasão nacional esses dois vegetais. Quanto à Bandeira atual, a Casa de Bragança, a que pertencia a D. Pedro I, é compreendida como símbolo de nossas matas e florestas.

Também compreendemos a veste como um elemento da cultura material que é perpassada por questões de sociabilidades e sensibilidades vinculadas à religiosidade de um povo, a partir de suas crenças e do poder que lhe é conferido como um objeto simbólico. Adentrando a cultura material, vemo-la numa perspectiva de investigação que abarca "[...] toda e qualquer coisa que tenha sido produzida materialmente pelo homem, para satisfazer suas necessidades básicas". Engloba, portanto, "a moradia, a produção de alimentos, a religiosidade, o lazer, a educação, a locomoção” (PEIXOTO, 2008, p. 88). Nesse aspecto, temos como parâmetro o método de abordagem de Prown (1982), cuja linha de estudo se configura inicialmente na descrição do objeto; aqui, pontuamos também a iconografia da imagem, enfatizando o estudo da devoção mariana neste país. E, dentre outras etapas propostas por esse autor, frisamos a importância do processo de interpretação e de dedução do objeto que, em tal caso, é a fonte primária, a síntese de uma série de manifestações e relações humanas.

As informações levantadas até o momento seguem o que primeiro assevera Brustoloni (1998). De acordo com esse autor, Aparecida é originalmente policromada e possui traços faciais de uma etnia branca. Seu manto nessa descrição apare- 
ce como azul escuro e forro vermelho granada, cores oficiais, pois, conforme normas de Dom João IV, do ano de 1646, essa aparência havia sido determinada para ornar as imagens tituladas como Imaculada Conceição.

Outra notícia sobre o manto de Aparecida aparece nesta assertiva: "Manto e Coroa da Imagem já constam de um inventário da Capela do ano de 1750, documento conservado no Arquivo da Cúria Metropolitana de Aparecida" (BRUSTOLONI, 1998, p. 18). Acerca disso, ressaltamos que em 4 de janeiro desse ano, foi feito um inventário que enumera diversas alfaias e preciosidades depostas aos pés dessa representação de Nossa Senhora. Em 25, também desse mesmo mês e ano, foi fundada a Irmandade de Nossa Senhora Aparecida, e pouco tempo depois, começaram as visitas oficiais da Autoridade eclesiástica.

Informamos, no intuito de descortinar os caminhos percorridos por essa imagem, o que nos servirá de apoio para o andamento da pesquisa (2017), que em 1743 ainda não estava fundado o bispado de São Paulo. Nesse ano, um Padre chamado José Alves Vilela, vigário da igreja de Santo Antônio de Guaratinguetá (SP), se dirigiu ao Bispo diocesano do Rio de Janeiro, em nome dele e dos devotos, para que se erigisse uma capela com o título da mesma Senhora da Conceição Aparecida no distrito dessa freguesia. Assim, entre 1717 a 1745, a administração dos bens de Aparecida esteve nas mãos da legítima autoridade eclesiástica do Bispo do Rio de Janeiro (MACHADO, 1975).

Aprofundando-nos, portanto, no vestuário de Aparecida, sabe-se, ainda que em o8 de dezembro de 1868 , essa escultura recebeu da princesa Isabel um manto de veludo azul, com 21 brilhantes que representavam a capital e as 20 províncias do Império. Em 1884, Aparecida ganhou uma coroa de ouro, cravejada de brilhantes, 24 diamantes maiores e 16 menores (BÖING, 2007). Em contrapartida, Brustoloni (1981) fala e mostra uma imagem de Aparecida, Figura 1, cujo manto possui ornamentações diferenciadas das que existem atualmente e da que é apresentada na descrição de Böing (2007) sobre o manto recebido da princesa Isabel. Também no museu da Basílica de Aparecida, podemos encontrar o manto utilizado na Coroação da escultura, em 1904, conforme mostra a Figura 2. De acordo com a própria Basílica, o manto da Figura 3 também fez parte da cerimônia de Coroação de Aparecida. Já a Figura 4 foi tirada em 1924 pelo fotógrafo André Benotti. 

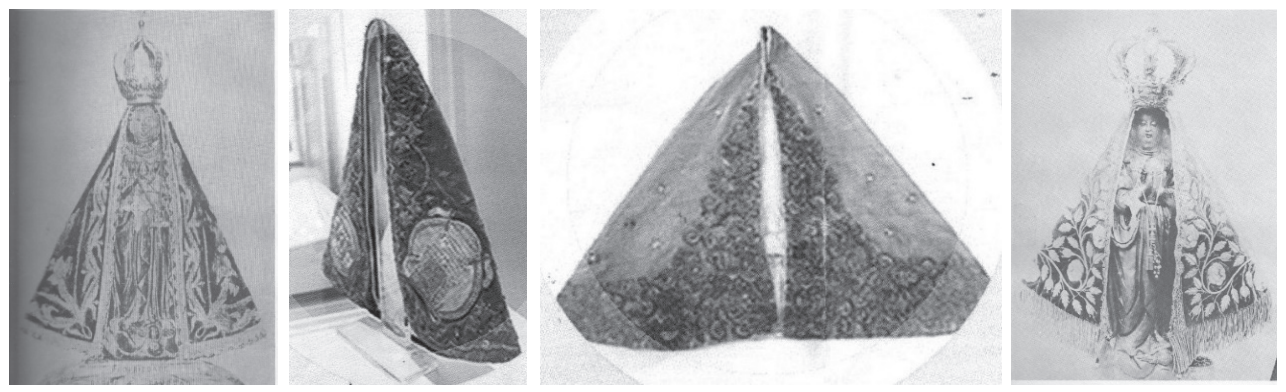

Quanto à sua vestimenta atual (2017), Aparecida porta as bandeiras do Brasil e do Vaticano, Figura 5. Esses emblemas foram postos na imagem após a sua proclamação como padroeira brasileira; logicamente, essa hipótese se apoia nas fotografias anteriores da imagem e no fato de que o Vaticano só foi criado em 1929, a partir do Tratado de Latrão, assinado pelo papa Pio XI e pelo ditador Benito Mussolini (CARLETTI, 2012).

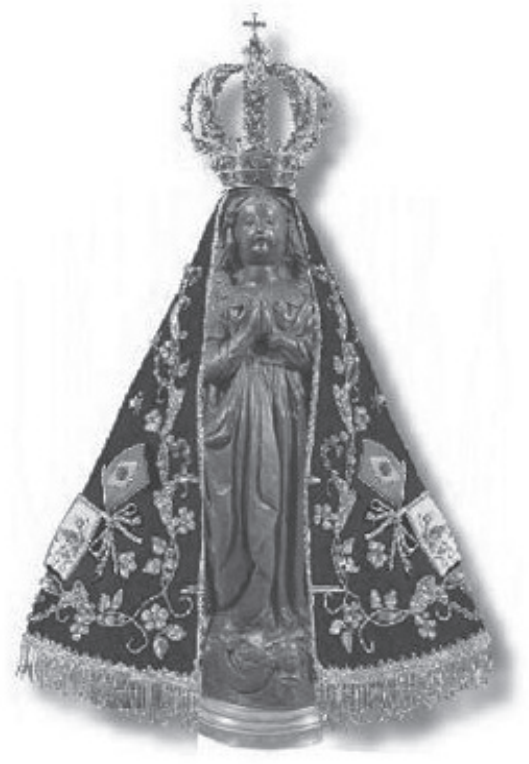

Figura 1 - Primeira foto da Imagem, tirada pelos fotógrafos franceses Robin e Favreau, 1869. Fonte: Brustoloni (1981).

Figura 2 - Manto mais antigo, da imagem original de Nossa Senhora Aparecida, na coroação da Imagem, em 1904. Exposto no museu da Basílica. Fonte: Cavalheiro (2015).

Figura 3 - Também foi usado nas cerimônias da Coroação no ano de 1904. Está guardado na reserva técnica do museu. Fonte: Cavalheiro (2015).

Figura 4-Imagem de Aparecida com manto. Fonte: Brustoloni (1981).

Figura 5 - Imagem de Nossa Senhora Aparecida: frente da peça, com manto.

Diante disso, observando o vestuário de Aparecida, antes, durante e depois do período em que a escultura foi considerada padroeira, na primeira fase do governo provisório de Getúlio Vargas (1930-1934), verificamos que o Manto de Aparecida 
não é o mesmo que conhecemos hoje, conforme imagem exposta acima, portando as bandeiras do Brasil e do Vaticano.

\section{Considerações finais}

Na década de 1930, na primeira fase da Era Vargas, a Igreja restabeleceu o catolicismo brasileiro que se via formalmente enfraquecido pela sociedade laica. É possível supor que, como ícones mediadores, os emblemas presentes no manto de Nossa Senhora Aparecida constituíram elementos intermediários, marcados tanto pelo sentimento patriótico laico e popular, proposto pelo Estado naquele período histórico, quanto pela busca da bem-aventurança celestial, propugnada pela Igreja Católica no Brasil, diante das incertezas políticas e sociais daquele momento histórico.

Esta pesquisa sobre os mantos da imagem da escultura de Nossa Senhora Aparecida, baseada em características ornamentais e simbólicas, relacionadas aos discursos religiosos, políticos e sociais, enuncia a relevância das vestes das imagens sacras. No caso de Nossa Senhora Aparecida, essa importância é compreendida pela presença de bandeiras brasileiras em sua ornamentação, assim como pela proclamação dela como padroeira brasileira no governo de Getúlio Vargas.

Dessa maneira, o vestuário pode ser observado como um símbolo de poder da Igreja e do Estado que medeia a articulação religiosa, política e social, aparando conflitos e acomodando as contradições nessa busca pelo estabelecimento de uma nação.

Assim, estudar como a política se manifesta, a partir de adaptações dos mantos de Aparecida, nos leva a investigar e identificar sinais, gestos e símbolos constituintes de uma "comunidade imaginada" como nação, reconhecendo os limites e os prolongamentos entre o religioso e o político, entre a devoção mariana a e identidade cívica. Chamamos nossa nação de comunidade imaginada "[...] porque, independentemente da desigualdade e da exploração efetivas que possam existir dentro dela, a nação é sempre concebida como uma profunda camaradagem horizontal" (ANDERSON, 2008, p. 34)

O fato de se atribuir as bandeiras do Brasil e do Vaticano ao manto de Nossa Senhora Aparecida, em anos posteriores à sua proclamação como padroeira do Brasil, assim como as transformações das suas vestimentas ao longo dos anos, certamente ainda têm muito a revelar em nossas pesquisas. 
NOTAS

1 Texto original em francês.

2 Texto original em espanhol.

3 O padroado era um "instituto jurídico" pelo qual o papa concedia aos reis direitos e privilégios sobre a Igreja (negócios eclesiásticos) e recebia, por meio de obrigações dos monarcas, recursos e proteção para os seus trabalhos.

4 Texto original em francês.

5 Texto original em francês.

6 Aldeia localizada no Alto Aragão, no Vale de Gistaín, extrema parte oriental de Sobrarbe, Espanha.

7 Texto original em francês.

8 Texto original em francês.

9 Consistia em dois painéis retangulares, de $55 \mathrm{~cm}$ de comprimento por $22,5 \mathrm{~cm}$ de largura, aos quais pertenciam ainda dois pedaços retangulares. Supõe-se que esses painéis fossem firmados a um mastro e levados à frente de procissõ̃es e cortejos. Eram cobertos de grande número de figuras de mosaico de madrepérola e conchas sobre fundo de lápis-lazúli. Nele se vê uma cena do banquete; da condução de animais ao sacrifício; de um grupo de prisioneiros e um grupo de guerreiros; e, finalmente, cenas de carros de guerra. Esses carros nos lembram de que os sumerianos os introduziram como máquinas de guerra nos combates que se travaram no fim do quarto milênio a. C. A cidade de Ur, uma importante cidade-estado da antiga Suméria, seria a lendária pátria de Abraão, na Caldéia, junto ao Eufrates, como se lê em Gênesis, capítulo 11, versículo 31.

\section{REFERÊNCIAS}

ALBERT-LLORCA. Marlène. La fabrique du sacré. Les vierges "miraculeuses" du pays valencien. Revue Genèses, Paris, v. 17, 1994. Disponível em: <http://www.persee.fr/ docAsPDF/genes_1155-3219_1994_num_17_1_1260.pdf>. Acesso em: 5 jan. 2017.

. Les statues habillées dans le catholicisme. Entre histoire de l'art, histoire religieuse et anthropologie. Archives de sciences sociales des religions, Paris, n. 164, p. 1123, 2013. Disponível em: < http://assr.revues.org/25380>. Acesso em: 27 mar. 2017.

ALVES, Andréa Maria Franklin de Queirós. Pintando uma imagem Nossa Senhora Aparecida - 1931: Igreja e Estado na Construção de um Símbolo Nacional. 2005. Dissertação (Mestrado em História) - Universidade Federal de Mato Grosso do Sul, Dourados, 2005.

ANDERSON, Benedict. Comunidades imaginadas. Tradução Denise Bottman. São Paulo: Companhia das Letras, 2008. 
ARGOLO, José Dirson. Análise da restauração de pinturas artísticas referenciada na intervenção em painéis de José Joaquim da Rocha, pertencentes ao Acervo da Santa Casa da Misericórdia, Salvador, Bahia. 2014. 513 f. Tese. (Doutorado em Artes Visuais) - Programa de Pós-Graduação em Artes Visuais, Universidade Federal da Bahia, Salvador, 2014.

BARTHOLEYNS, Gil. Le moment Chrétien. Fondation Antique de la Culture Vestimentaire Médiévale. In: GHERCHANOC, Florence; HUET, Valérie. Vêtements Antiques: s'habiller, se déshabiller dans les mondes anciens. Arles: Errance, 2012. p. 113-134.

BÖING, Mafalda Pereira. Nossa Senhora Aparecida: a Padroeira do Brasil. São Paulo: Loyola, 2007.

BRUSTOLONI, Júlio J. A Senhora da Conceição Aparecida: História da Imagem da Capela das Romarias. 2. ed. Aparecida: Editora Santuário, 1981.

. História de Nossa Senhora da Conceição Aparecida: a imagem, o santuário e as romarias. 10. ed. Aparecida: Editora Santuário, 1998.

CARLETTI, Anna. O internacionalismo vaticano e a nova ordem mundial: a diplomacia pontifícia da Guerra Fria aos nossos dias. Brasília: Fundação Alexandre Gusmão, 2012. 226 p.

CAVALHEIRO, Elisangela. Os mantos da Mãe Aparecida. Santuário Nacional Aparecida, 12 out. 2015. Disponível em: <http://www.a12.com/santuario-nacional/noticias/ detalhes/os-mantos-da-mae-aparecida-1>. Acesso em: 17 dez. 2015.

COIMBRA, Raimundo Olavo. A Bandeira do Brasil: raízes histórico-culturais. 3. ed. Rio de Janeiro: IBGE, 200o. Disponível em: <http://biblioteca.ibge.gov.br/index.php/ biblioteca-catalogo view $=$ detalhes\&id $=27081>$. Acesso em: 9 fev. 2017.

COULANGES, Numa-Denys Fustel de. A cidade antiga: estudo sobre o culto, o direito e as instituições da Grécia e de Roma. Tradução Frederico Ozanam Pessoa de Barros. São Paulo: Editora das Américas S.A. Edameris, 2006. Disponível em: < http://bibliotecadigital.puc-campinas.edu. br/services/e-books/Fustel\%2ode\%2oCoulanges-1.pdf>. Acesso em: 12 fev. 2017.

DELFOSSE, Annick. Vêtir la Vierge: une grammaire identitaire. In: Quand l'habit faisait Le moine. Une histoire du vêtement civil et religieux em Luxembourg et au-delà. Bastogne, 2004. Musée en Piconrue. Catálogo de exposição. 2004. p.199-208. 
Quand Marie entre en politique. La Vierge et l'État moderne. In: DELVILLE, Jean-Pierre et alli: Marie, figures et réception. Enjeux historiques et théologiques. Colloque international, Liège, 22 octobre, et Louvain-la-Neuve, 23 octobre 2008 (2012). Disponível em: <https://www.academia.edu/3585640/ Quand_Marie_entre_en_politique._La_Vierge_et_1\%C3\%89tat_moderne>. Acesso em: $11 \mathrm{fev} .2017$.

LIVRO do Gênesis. In: Bíblia sagrada. Tradução dos Monges de Maredsous (Bélgica). 145. ed. rev. São Paulo: Ed. Ave Maria, 2001.

LUSTOSA, Oscar. Catequese católica no Brasil: para uma história da evangelização. São Paulo: Edições Paulinas, 1992.

MACHADO, João Corrêa. Aparecida: Na história; na literatura. Campinas,SP: Edições do autor, 1975.

MOREIRA, Fuviane Galdino. Análise Tipológica dos Estofamentos das Esculturas Policromadas do Acervo de Arte Sacra do Museu Solar Monjardim. 2009. 149 f. Monografia (Bacharelado em Artes Plásticas) - Curso de Artes Plásticas, Universidade Federal do Espírito Santo, Vitória, 2009.

- Mantos de Aparecida: religião, política e identidade nacional. 2017. $31 \mathrm{f}$. Trabalho acadêmico de conclusão da disciplina História e Teoria das Artes Visuais I (Doutorado em Artes) - Programa de Pós-Graduação em Artes Visuais, Universidade Federal do Rio de Janeiro, Rio de Janeiro, 2017.

ORTIZ, Renato. Mundialização: saberes e crenças. São Paulo: Brasiliense, 2006.

PEIXOTO, Luciana da Silva. Arqueologia e patrimônio: o urbanismo na ótica da cultura material. In: CERQUEIRA, Fábio Vergara et al (Org.). Educação patrimonial: perspectivas multidisciplinares. Pelotas: Instituto de Memória e Patrimônio, 2008. p. 87-90.

PUCCIO, Deborah. Mieux vaut habiller les saints que déshabiller les ivrognes. Vêtir les saints à San Juan de Plan (Aragon). Terrain, Paris, n. 38, p. 141-152, 2002. Disponível em: $<$ http://terrain.revues.org/1975>. Acesso em: 7 fev. 2017.

PROWN, Jules David. An Introduction to material culture Theory and method. Winterthur Portfolio, v. 17, n. 1, p. 1-19, 1982. SILVA, Paulo Julião da. A Igreja Católica e as Relações Políticas com o Estado na Era Vargas. In: XIII Simpósio Nacional da ABHR, 2012, São Luís. Anais do XIII Simpósio Nacional da $A B H R$, São Luís, v. 13, p. 1-11, 2012.

SCHEFFLER, Felix. ¿"Poesía" o "Pecado Mortal"? La pintura de desnudo en la España de Calderón. In: Actas / Duodécimo Coloquio Anglogermano sobre Calderón, 1999, Leipzig. 
Deseo, sexualidad y afectos en la obra de Calderón. Leipzig: Franz Steiner Verlag Stuttgart, 1999. v. 9, p. 9-40.

SOUZA, Juliana Beatriz Almeida de. Virgem mestiça: devoção à Nossa Senhora na colonização do Novo Mundo. Revista Tempo, Niterói, v. 6, n. 11, p.77-92, 2001. - Construção da memória e devoção na escolha de Nossa Senhora Aparecida como padroeira do Brasil. In: XIV Jornadas Interescuelas/Departamentos de História de la Facultad de Filosofía y Letras. Universidad Nacional de Cuyo, Mendoza, p. 9-30, 2013. Disponível em: <http://cdsa. aacademica.org/ooo-010/314.pdf>. Acesso em: 6 fev. 2017.

TREXLER, Richard C. Habiller et deshabiller les images. esquise d'une analyse. In: Durand, Françoise; SPRESER, Michael; WIRTH, Jean (Coord.). L'image et la production du sacré. Paris: Klincksieck, 1991. p. 195-231.

VASCONCELOS, Francisco A. Notas sobre a liderança de Dom Sebastião Leme no Brasil. Reflexus, Vitória v. 9, p. 295-316, 2015. Disponível em: <http://revista.faculdadeunida.com.br/index.php/reflexus/article/view/298>. Acesso em: 7 fev. 2017.

Aceito em: 19/07/2017

Aprovado em: 06/11/2017

\section{FUVIANE GALDINO MOREIRA}

moreira.fuvi@hotmail.com

Doutoranda do Programa de Pós-Graduação em Artes Visuais da Universidade Federal do Rio de Janeiro (UFRJ), na área de História e Teoria da Arte, linha de Pesquisa Imagem e Cultura. Brasil 